\title{
2003 The prognostic significance of the "no-reflow" phenomenon and infarct size to left ventricular remodeling following ST segment elevation acute myocardial infarction
}

\author{
Teresa M de caralt*, Jose T Ortiz, Rosario J Perea, Victoria Delgado, \\ Marta Sitges, Carles Pare, Pedro Arguis and Marcelo Sanchez
}

Address: Hospital Clinic, Barcelona, Spain

* Corresponding author

from I th Annual SCMR Scientific Sessions

Los Angeles, CA, USA. I-3 February 2008

Published: 22 October 2008

Journal of Cardiovascular Magnetic Resonance 2008, I0(Suppl I):A272 doi:I0.II86/I532-429X-I0-SI-A272

This abstract is available from: http://jcmr-online.com/content/I0/SI/A272

(C) 2008 de caralt et al; licensee BioMed Central Ltd.

\section{Introduction}

Infarct size and no reflow phenomenon also known as microvascular obstruction (MO) have been associated with adverse left ventricular (LV) remodeling following ST segment elevation acute myocardial infarction (STEMI).

\section{Purpose}

We evaluated the relative contribution of each one of these factors in the left ventricular remodeling.

\section{Methods}

A standard cine and delayed enhanced cardiac magnetic resonance (de-CMR) was performed acutely and at 6 months in 26 patients following their first STEMI, treated with primary percutaneous intervention. LV end-diastolic (LVEDV), LV end-systolic volumes (LVESV), ejection fraction (EF), and infarct size (\% of LV mass) were calculated. The presence of MO was defined as any hypoenhancement within the late-hyperenhanced areas.

\section{Results}

Mean infarct size was $24.3 \pm 15 \% \mathrm{LV}$ mass. The initial infarct size highly correlated with the final EF $(\mathrm{r}=0.76, \mathrm{p}<$ 0.001), final LVEDV $(r=0.53, p<0.001)$ and LVESV $(r=$ $0.67, \mathrm{p}<0.001)$. Eight subjects $(33 \%)$ had $\mathrm{MO}$ on ceCMR images. Patients with MO had significantly larger LVEDV, LVESV and lower EF at baseline and at 6 months. Additionally, they also had larger initial infarct sizes. However, by multiple linear regression analysis, infarct size was the only independent predictor of final EF ( $\mathrm{B}=$ $\left.0.76, R^{2}=0.58, p<0.001\right)$ and final LVESV $\left(B=0.67, R^{2}\right.$ $=0.45, \mathrm{p}<0.001)$. Table 1 .

\section{Conclusion}

No-reflow or MO phenomenon is more often seen in patients with large infarct sizes. Both extensive infarction and the presence of microvascular obstruction are associated with adverse left ventricular remodeling. However, infarct size appears to be a stronger determinant of final ejection fraction and left ventricular volumes. 
Table I: Infarct size and MO phenomenon have been associated with adverse ventricular remodeling following STEMI. The relative contribution of these factors is unknown. Infarct size appears to be a stronger determinant of final ejection fraction and left ventricular volumes.

\begin{tabular}{llll}
\hline & MOpresent & MO absent & $P$ \\
\hline EF\% baseline & $43.8 \pm 11.2$ & $54.9 \pm 11.3$ & $<0.05$ \\
EF\% follow-up & $49 \pm 8.6$ & $59.1 \pm 11.4$ & $<0.05$ \\
LVEDVml baseline & $153 \pm 24.6$ & $130.2 \pm 28.1$ & $=0.05$ \\
LVEDVml follow-up & $192,8 \pm 52.9$ & $144.7 \pm 24.8$ & $<0.05$ \\
LVESV ml baseline & $88.2 \pm 28.5$ & $58.2 \pm 26.5$ & $<0.01$ \\
LVESV ml follow-up & $101.1 \pm 42.7$ & $58.5 \pm 26.5$ & $<0.01$ \\
Infarct size\% LV mass, bseline & $134.7 \pm 11.7$ & $19.6 \pm 14$ & $<0.05$ \\
\hline
\end{tabular}

Publish with Bio Med Central and every scientist can read your work free of charge

"BioMed Central will be the most significant development for disseminating the results of biomedical research in our lifetime. "

Sir Paul Nurse, Cancer Research UK

Your research papers will be:

- available free of charge to the entire biomedical community

- peer reviewed and published immediately upon acceptance

- cited in PubMed and archived on PubMed Central

- yours - you keep the copyright

Submit your manuscript here:

http://www.biomedcentral.com/info/publishing_adv.asp 